\title{
Biodiversity of a continental shelf soft-sediment macrobenthos community
}

\author{
Kari Elsa Ellingsen* \\ Section of Marine Zoology and Marine Chemistry, Department of Biology, University of Oslo, PO Box 1064 Blindern, \\ 0316 Oslo, Norway
}

\begin{abstract}
Soft-sediment macrobenthos data from the southern part of the Norwegian continental shelf was used to study faunal patterns and spatial variability, and to evaluate different measures of marine biodiversity. Water depth and sediment characteristics were remarkably uniform over the spatial sampling scale of $130 \times 70 \mathrm{~km}$, and relations between measured environmental variables and community structure were weak. Out of 175 recorded species, $10 \%$ spanned the entire sampling area (16 sites), while $27 \%$ were restricted to a single site. The number of rare species was positively correlated with species richness. Common species were widely spatially distributed, while species of low abundance had strongly compressed range sizes. The distribution of species varied among the 4 dominant taxonomic groups: the polychaetes, crustaceans, molluscs, and echinoderms. Polychaetes were the most common taxonomic group and had the highest proportion of widespread species. Whittaker's beta diversity measure $\left(\beta_{\mathrm{W}}\right.$, extent of change in species composition among sites) varied among the dominant taxonomic groups and was highest for crustaceans, followed by molluscs. Neither the number of shared species nor the complementarity (biotic distinctness) between all pairwise permutations of sites was linked to spatial distance. However, the Bray-Curtis similarity between all pairwise combinations of sites was a function of spatial arrangement and was the most sensitive measure of beta diversity. Faunal pattern changed across the study area, despite the uniform habitat. Furthermore, faunal pattern and variability changed with scales. The measurement of biodiversity is therefore dependent on spatial scale, and cross-scale studies are important. The abstract concept of biodiversity as the 'variety of life' cannot be encapsulated by a single measure. Distributions of species and community differences should be taken into account in addition to species diversity when measuring marine biodiversity and planning conservation areas, and more than 1 taxonomic group should be studied in a system.
\end{abstract}

KEY WORDS: Soft-sediment communities $\cdot$ Marine biodiversity $\cdot$ Scales $\cdot$ Species richness $\cdot$ Rarity Beta diversity Resale or republication not permitted without written consent of the publisher

\section{INTRODUCTION}

Oceans cover about $70 \%$ of the surface area of the earth, and sedimentary habitats ranging from gravel to fine mud cover most of the sea-bottom (Snelgrove et al. 1997). Soft-sediment habitats are common in coastal areas throughout the world, but only a small fraction of the macrobenthos that reside on or are buried in sediments has been described (Snelgrove 1999). Human activities, directly or indirectly, are now the primary cause

*E-mail: k.e.ellingsen@bio.uio.no of changes to marine biological diversity (biodiversity), especially in coastal areas. The present rate of habitat degradation in marine ecosystems is alarming (Gray 1997, Snelgrove et al. 1997), and conservation of marine biodiversity is of critical importance. The principal questions are how marine biodiversity should be measured and how conservation areas should be identified.

The most prevalent use of the term 'biodiversity' is as a synonym for the 'variety of life' (Gaston 1996). Biodiversity covers the range of variation in and variability among systems and organisms at the levels of ecological or community, organismal, and genetic diversity (Harper 
\& Hawksworth 1994, Heywood \& Watson 1995). Here I will consider species diversity and distributions of species as well as community differences within a single habitat type. Most biodiversity studies relate to terrestrial systems, and the terminology originates from terrestrial literature and traditions. Techniques used for a long time in terrestrial studies of biodiversity are now being applied to marine systems. However, marine systems differ from terrestrial systems in a number of ways, and paradigms concerning patterns of biodiversity in terrestrial systems may not be applicable to marine situations (May 1994, Gray 1997, Heip et al. 1998). Many benthic species have pelagic larvae that remain in the water for days or months, and since marine systems are more 'open' and barriers to dispersal are relatively weak, unlike most terrestrial systems, species can disperse over much broader ranges.

The number of species has been the traditional measure of biodiversity in ecology and conservation, but the biodiversity of an area is much more than the 'species richness' (Harper \& Hawksworth 1994). As the number of individuals per species varies in a given area, a variety of diversity indices combine the species richness and how evenly the individuals are distributed among the species (see Magurran 1988 for an overview). Here I follow Peet (1974) in calling these indices 'heterogeneity diversity'. The 2 most popular criteria for a conservation strategy are species richness and 'rarity' (Prendergast et al. 1993). 'Rare' species can simply be regarded as those having low abundance or small range size, and the terms 'common' (or 'abundant') and 'widespread' can be used as the antitheses of 'rare' (Brown 1984, Gaston 1994). Species with a restricted range and that occur in few habitats are usually the most vulnerable to environmental change (Thomas \& Mallorie 1985). As the loss of marine habitats caused by a variety of human activities is great in coastal areas, range size rather than abundance is used in this study to define rarity.

The partitioning of species richness into alpha $(\alpha$, within-area), beta ( $\beta$, between-area), and gamma $(\gamma$, within-area) components to characterise different aspects or levels of diversity was first proposed by Whittaker (1960). The use of scales describing $\alpha$ (local) and $\gamma$ (regional) diversity varies among authors, but here $\alpha$ is used as the number of species at a site and $\gamma$ as the species richness in the whole study area or region. Most studies of $\beta$ diversity have focused on a single taxon, but patterns in $\beta$ diversity may be expected to vary among taxa (Harrison et al. 1992). Furthermore, studies of $\beta$ diversity are traditionally concerned with samples arranged along 1 or more environmental gradients (Whittaker 1960, Wilson \& Shmida 1984). In marine soft-bottom studies multivariate methods have proved much more sensitive to small changes in faunal composition than species richness and diversity indices
(Gray et al. 1990, Warwick \& Clarke 1991, Warwick \& Clarke 1993). A multivariate measure of $\beta$ diversity may be expected to give additional information to other measures of $\beta$ diversity.

Most surveys cannot sample large areas of marine systems, so much data relate to only small areas of the seafloor (Ward et al. 1998). However, it is likely that the community structure varies greatly within any latitudinal area (Gray 2000), and a comparison of only a few sites between areas may be insufficient. Furthermore, pattern and variability are likely to change with scale (Levin 1992, Thrush et al. 1997b, Ward et al. 1998), and the measurement of marine biodiversity may therefore be dependent on spatial scale.

Soft-sediment macrobenthos data from the southern part of the Norwegian continental shelf are used in this study. Sediment type or depth are commonly assumed to be the prime factors in structuring benthic assemblages (Sanders 1968, Gray 1974, Snelgrove et al. 1997). However, the area was chosen to study faunal patterns and variability over a rather large area of similar sediment properties and uniform depth (i.e. a single habitat type). Faunal pattern and variability and the importance of environmental heterogeneity will be the subject of a further paper. In this study the methodological problems in measurement of the number of species and individuals in a given area as well as the insufficiency of univariate measures of biodiversity were considered. Moreover, the distribution of species range sizes within the 4 dominant taxonomic groups in soft-sediment communities - the polychaetes, crustaceans, molluscs and echinoderms - and the relations between local abundance and range size were investigated. Whittaker's $(1960,1972) \beta_{\mathrm{W}}$ was also compared among the 4 dominant taxonomic groups. Furthermore, the number of shared species, the complementarity (biotic distinctness) (Colwell \& Coddington 1994), and the multivariate Bray-Curtis similarity (Bray \& Curtis 1957) between all pairwise permutations of sites were related to geographic distance and used as other measures of $\beta$ diversity. Finally, changes in faunal patterns and variability with increasing geographic scale and across the study area were investigated.

\section{MATERIAL AND METHODS}

The data were collected in May 1996 at the southern part of the Norwegian continental shelf as part of a routine environmental monitoring survey of the effects of the oil and gas industry on the seabed. The Norwegian Pollution Control Authority (SFT) has divided the Norwegian continental shelf into 'regions', of which this data set is from the southernmost region (Region I). Total sampling coverage spanned approximately 


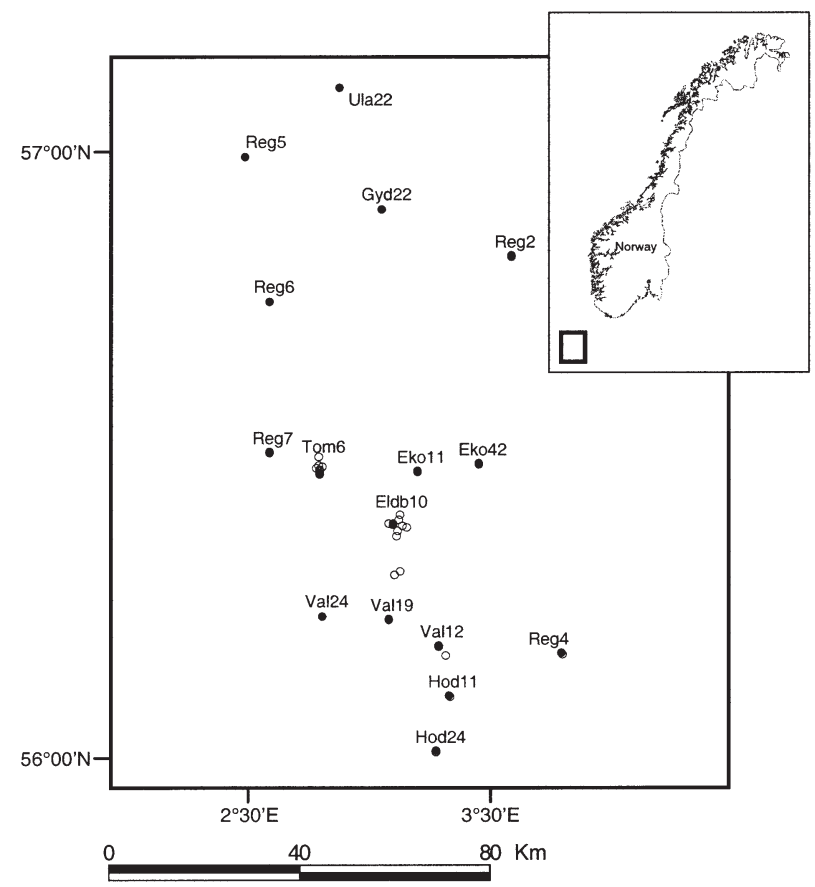

Fig. 1. Geographic position of 39 uncontaminated sampling sites in Region I at the southern part of the Norwegian continental shelf. $\bullet$ : sites included in the regional scale data set, i.e. 16 sites; o: sites not included in the regional scale data set; all but 1 are included in the 2 data sets at intermediate scales

$130 \mathrm{~km}$ in a south-north direction and approximately $70 \mathrm{~km}$ from east to west $\left(56^{\circ} 02^{\prime}\right.$ to $57^{\circ} 08^{\prime} \mathrm{N}, 2^{\circ} 30^{\prime}$ to $3^{\circ} 49^{\prime} \mathrm{E}$, see Fig. 1). The positioning equipment was a differential global positioning system with an accuracy within $\pm 10 \mathrm{~m}$. Depth at 16 sites in the study area was relatively constant (ranging from 65 to $74 \mathrm{~m}$ ), and the sediment, dominated by fine sand, was remarkably uniform (Table 1).

Biological, physical, and chemical samples were taken with a $0.1 \mathrm{~m}^{2}$ van Veen grab. At each site 5 replicates for analyses of macrobenthos were taken. Biological samples were sieved on a $1 \mathrm{~mm}$ round hole diameter sieve, and retained fauna were fixed in formalin for later identification to lowest practical taxonomic level. Three additional grabs were taken at each site for analyses of sediment variables. Sub-samples were taken from the upper $5 \mathrm{~cm}$ of the grabs for analyses of total organic matter, sediment median grain size, sorting, skewness, and kurtosis, and from the upper $1 \mathrm{~cm}$ for chemical analyses of hydrocarbons and metals. Additional details of sampling and analyses are given in Mannvik et al. (1997). Procedures were in accordance with the methods recommended by SFT (Anonymous 1990).

Data analyses. Taxonomic groups not properly sampled by the methods used (Nematoda, Foraminifera), colonial groups (Porifera, Hydrozoa, Bryozoa), pelagic crustaceans (Calanoida, Mysidacea, Hyperiidae, Euphausiacea), and juveniles were excluded from the data analyses. Unidentified species were only included if they could not be mistaken for other identified species. Data analyses were done on species abundance data pooled over 5 replicated sampling units (grabs) from each site. Only data from sites unaffected by oil or gas activities were used. For each field these sites were identified by univariate $\left(S, N, E x p H^{\prime}, 1 /\right.$ Simpson) and multivariate (CLUSTER, MDS) analyses of faunal data and measured concentrations of hydrocarbons and metals (the results are not given here, see description

Table 1. Summary of depth, sediment characteristics, and univariate measures of community structure (per $\left.0.5 \mathrm{~m}^{2}\right)$ at 16 sites at the southern part of the Norwegian continental shelf. Sites ordered in a sequence from south to north. Md $\varphi$ : median grain size; TOM: \% total organic matter; $S$ : the number of species; $N$ : the number of individuals; ExpH': the exponentiated form of the Shannon formula; 1/Simpson: the reciprocal of Simpson's index

\begin{tabular}{|c|c|c|c|c|c|c|c|}
\hline Site & Depth (m) & $M d \varphi$ & TOM (\%) & $S$ & $N$ & ExpH' & 1/Simpson \\
\hline Hod24 & 67 & 3.53 & 0.92 & 74 & 924 & 12.2 & 4.1 \\
\hline Hod11 & 70 & 3.53 & 0.91 & 67 & 638 & 25.6 & 13.9 \\
\hline Val12 & 65 & 3.52 & 0.81 & 68 & 484 & 23.6 & 12.1 \\
\hline Val24 & 67 & 3.50 & 0.81 & 69 & 511 & 26.5 & 15.9 \\
\hline $\operatorname{Reg} 4$ & 68 & 3.48 & 0.95 & 81 & 502 & 36.0 & 16.6 \\
\hline Val19 & 67 & 3.52 & 0.80 & 70 & 580 & 31.4 & 18.5 \\
\hline Eldb10 & 69 & 3.54 & 0.86 & 63 & 540 & 29.4 & 18.8 \\
\hline Tom6 & 74 & 3.57 & 1.20 & 68 & 451 & 40.1 & 28.0 \\
\hline $\operatorname{Reg} 7$ & 72 & 3.53 & 0.93 & 61 & 576 & 24.0 & 15.5 \\
\hline Eko11 & 72 & 3.52 & 0.86 & 71 & 551 & 29.7 & 16.4 \\
\hline Eko42 & 67 & 3.52 & 0.86 & 58 & 486 & 20.7 & 12.8 \\
\hline Reg6 & 70 & 3.56 & 0.95 & 64 & 589 & 23.3 & 10.9 \\
\hline Reg2 & 65 & 3.50 & 0.95 & 67 & 605 & 27.0 & 17.2 \\
\hline Gyd22 & 65 & 3.50 & 0.97 & 65 & 452 & 25.6 & 15.2 \\
\hline Reg5 & 69 & 3.59 & 0.94 & 80 & 849 & 14.1 & 5.2 \\
\hline Ula22 & 71 & 3.50 & 0.82 & 59 & 505 & 17.2 & 7.4 \\
\hline
\end{tabular}


of methods in the following sections). The resulting 39 unaffected sites (Fig. 1) were located without reference to the present study. Data sets from local (i.e. a single site), intermediate, and regional (i.e. the whole study area) scales were used in this study. From data sets at intermediate scales (Fig. 1) only 1 site from each group was selected at random and included in the regional scale data set. The reason for this selection was to distribute the sites relatively evenly through the whole study area (i.e. the distances between adjacent sites should be as similar as possible). In the following analyses a resulting data set of 16 sites from the whole area were used if not stated otherwise.

As univariate measures of diversity, species richness $(S)$, the exponentiated form of the Shannon-Wiener in$\operatorname{dex}\left(\mathrm{ExpH}^{\prime}\right)$ (log base 2), and the reciprocal of Simpson's index (1/Simpson) were used (see e.g. Whittaker 1972, Magurran 1988). Hill (1973) labelled these diversity measures $N_{0}, N_{1}$ and $N_{2}$, respectively. $S$ is the number of all species regardless of abundance. ExpH' is most affected by species in the middle of the species rank sequence, whereas 1/Simpson is primarily a measure of dominance (Whittaker 1972). Thus $S$ and the 2 heterogeneity diversity indices (ExpH' and 1/Simpson) measure different aspects of species diversity. The above measurements are implemented in the Plymouth Routines in Multivariate Ecological Research (PRIMER) package, described in Clarke \& Warwick (1994).

Whittaker (1960) established a simple measure of $\beta$ diversity, $\beta=\gamma / \alpha$, where $\alpha$ is the diversity value for an individual sample and $\gamma$ is the value resulting from merging a number of individual samples. Whittaker (1972) stated that the mean number of species in $\alpha$ samples (i.e. $\bar{\alpha}$ ) could be used, and recommended modifying the measure of $\beta$ diversity as the ratio given minus 1.0 (i.e. $(\gamma / \bar{\alpha})-1)$. In the present study $\beta$ diversity was measured as $\beta_{\mathrm{W}}=(\gamma / \bar{\alpha})-1$. Here $\gamma$ is the total number of species in the whole sampling area (regional richness), $\bar{\alpha}$ is the average number of species per individual sample, and 1 sample or site is the sum of 5 grabs (local richness). This measures the proportion by which the whole area is richer than the average sites within it. Its formulation does not assume a gradient structure and is the measure of choice when samples cannot be arranged along a single gradient (Wilson \& Shmida 1984), as was the case in the present study. $\beta_{\mathrm{W}}$ was also used to examine pairwise differences between sites. In pairwise $\beta_{\mathrm{W}}$ (as opposed to overall) $\gamma$ is the number of species in the 2 sites combined. $\beta$ diversity or species turnover is based on ratios or differences and is not related to spatial scales, in contrast to $\alpha$ and $\gamma$ diversity. $\beta$ diversity is the extent of change in species composition of communities among the samples of a data set or along a gradient (Whittaker 1975).
Site sequences were randomised (without replacement) for the calculation of species accumulation curves. Following the terminology of Colwell \& Coddington (1994), uniques are species restricted to a single site, duplicates are species occurring at exactly 2 sites only, singletons are species represented by a single individual, and dubletons are species represented by only 2 individuals. The non-parametric Chao2 method (Chao 1987) was used to estimate the true species richness. Here Chao $2=\operatorname{Sobs}+\left(Q_{1}{ }^{2} / 2 Q_{2}\right)$, where Sobs is the number of species observed in all samples pooled, $Q_{1}$ is the frequency of uniques, and $Q_{2}$ is the frequency of duplicates. According to Colwell \& Coddington (1994) Chao2 provides the least biased estimates of species richness for small numbers of samples. The number of species shared for each possible pair of samples was used as a second measure of $\beta$ diversity. As a third measure of $\beta$ diversity, biotic distinctness, or 'complementarity', between all pairwise combinations of sites was used (Colwell \& Coddington 1994). Complementarity between 2 sites is the total number of unshared species divided by the total species richness for the 2 sites. The percentage of species that are complementary varies from zero (when the samples are identical) to $100 \%$ (when the samples are completely distinct). The above measurements are included in the EstimateS software (Colwell 1997). For calculations of range size-local abundance relations, local species abundance values were averaged across space including only non-zero counts.

A similarity matrix was constructed using square root transformation and the Bray-Curtis coefficient (Bray \& Curtis 1957). As a fourth measure of $\beta$ diversity the Bray-Curtis similarity between all pairwise permutations of sites was used. Hierarchical, agglomerative classification (CLUSTER), employing group-average linking (e.g. Clifford \& Stephenson 1975) and ordination by non-metric multidimensional scaling based on the Bray-Curtis similarity matrix (e.g. Kruskal \& Wish 1978, Clarke \& Green 1988), was used. Relations between faunal pattern and various subsets of environmental variables were examined using the BIO-ENV procedure (Clarke \& Ainsworth 1993). Environmental variables analysed were depth, latitude, longitude, total organic matter, median grain size, sorting (inclusive standard deviation), skewness, kurtosis, and percentage silt-clay fraction $(<0.063 \mathrm{~mm})$. Scatter plots of all pairwise combinations of environmental variables indicated that conversion to approximate normality using a $\log (1+N)$ transformation was appropriate before multivariate analyses for all variables with the exception of depth, latitude, and longitude, which were not transformed. Matrices derived from all possible combinations of environmental variables were computed using normalised Euclidean distance. The 
Table 2. Pairwise Spearman rank correlations between environmental variables and biotic diversity $\left({ }^{*} \mathrm{p}<0.05\right.$, all others $\mathrm{p}>0.05$; $\mathrm{n}=16$ for all correlations). TOM: total organic matter (\%); silt-clay: fraction of sediment < $0.063 \mathrm{~mm}(\%)$; Md $\varphi$ : median grain size; $S k_{I}$ : skewness; $\sigma_{I}$ : sorting; $K_{G}$ : kurtosis; $S$ : the number of species; ExpH': the exponentiated form of the Shannon formula; 1/Simpson: the reciprocal of Simpson's index

\begin{tabular}{|c|c|c|c|c|c|c|c|c|c|c|c|}
\hline & Latitude & Longitude & Depth (m) & TOM & Silt-clay & $M d \varphi$ & $S k_{I}$ & $\sigma_{I}$ & $K_{G}$ & $S$ & $E_{x p} H^{\prime}$ \\
\hline Longitude & $-0.61^{*}$ & & & & & & & & & & \\
\hline Depth (m) & 0.14 & -0.39 & & & & & & & & & \\
\hline TOM & 0.31 & -0.16 & 0.15 & & & & & & & & \\
\hline Silt-clay & $-0.66^{*}$ & 0.24 & 0.13 & 0.17 & & & & & & & \\
\hline$M d \varphi$ & -0.02 & -0.45 & $0.50^{*}$ & 0.22 & 0.36 & & & & & & \\
\hline$S k_{I}$ & -0.26 & -0.18 & 0.43 & 0.20 & $0.58^{*}$ & $0.91^{*}$ & & & & & \\
\hline$\sigma_{I}$ & -0.10 & -0.11 & 0.17 & 0.27 & 0.40 & 0.03 & 0.10 & & & & \\
\hline$K_{G}$ & -0.30 & 0.10 & 0.07 & 0.18 & $0.56^{*}$ & -0.19 & -0.01 & $0.84^{*}$ & & & \\
\hline$S$ & -0.39 & 0.26 & -0.16 & 0.04 & 0.36 & -0.06 & 0.15 & 0.46 & 0.39 & & \\
\hline ExpH' & -0.21 & 0.25 & 0.12 & 0.10 & 0.32 & -0.26 & -0.21 & 0.11 & 0.31 & 0.24 & \\
\hline 1/Simpson & -0.13 & 0.14 & 0.11 & 0.10 & 0.31 & -0.16 & -0.16 & 0.04 & 0.22 & 0.05 & $0.95^{*}$ \\
\hline
\end{tabular}

environmental variables were normalised (subtracting the mean across sites and dividing by standard deviation) because the variables need to be reduced to a common measurement scale because of different initial units. The Spearman rank correlation was used as a measure of agreement between each of the abiotic matrices and the biotic Bray-Curtis similarity matrix. The above non-parametric multivariate techniques are included in the PRIMER package.

A multivariate Mantel correlogram (Oden \& Sokal 1986, Sokal 1986) was computed to describe the spatial structure of species assemblages, using the R package (Legendre \& Vaudor 1991). Geographic (Euclidean) distances were computed between all pairwise combinations of sites, and the resulting distance matrix was recorded into distance classes, created with equal width using Sturge's rule (Legendre \& Legendre 1998). This matrix of distance classes gives rise to model matrices, different for each distance class. A biotic Bray-Curtis similarity matrix was compared with all the model distance matrices in turn, and normalised Mantel statistics $\left(\mathrm{r}_{\mathrm{M}}\right)$ were computed. The statistics were tested for significance using 999 permutations, and a global test of significance of the resulting Mantel correlogram was carried out using the Bonferroni method (Legendre \& Fortin 1989).

\section{RESULTS}

\section{Species richness and heterogeneity diversity}

Local species richness or alpha diversity $(S)$ was relatively low, ranging from 58 to 81 species (Table 1). Sample species richness and heterogeneity diversity (ExpH' and 1/Simpson) had no significant relation with measured environmental variables (Table 2 ). The heterogeneity diversity of the 4 dominant taxonomic

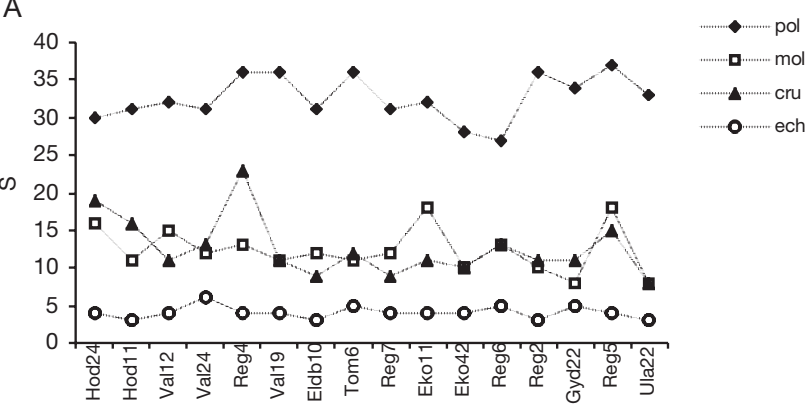

B
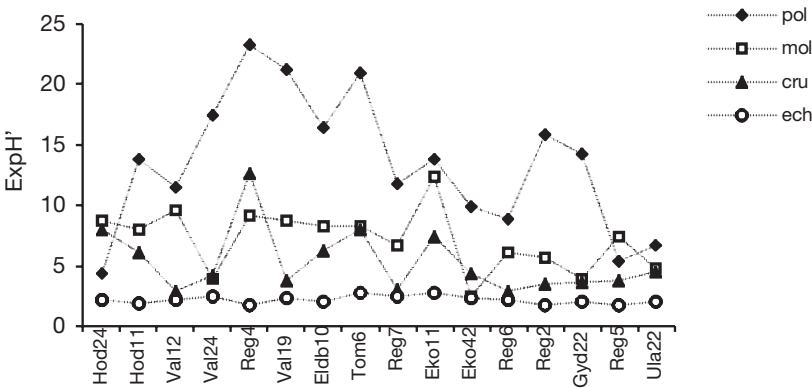

cru

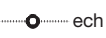

C

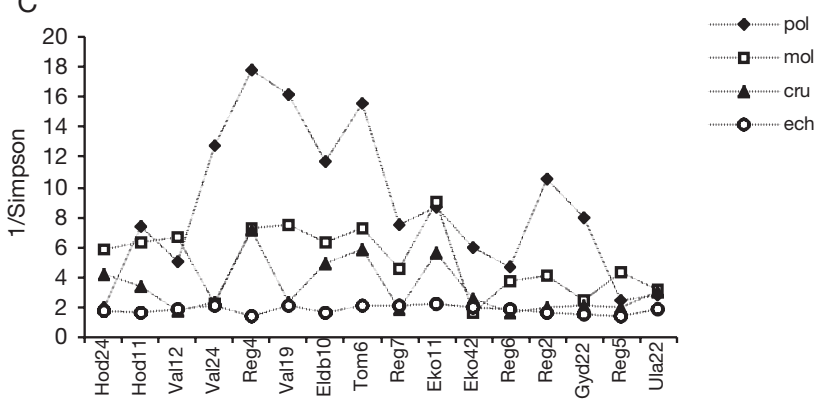

Fig. 2. Univariate measures of local community structure within dominant taxonomic groups. Samples are ordered in a sequence from south to north in the study area. (A) Species richness $(S)_{i}$ (B) the exponentiated form of the Shannon formula $\left(\operatorname{ExpH} H^{\prime}\right.$ ) (using log base 2); (C) the reciprocal of Simpson's index (1/Simpson). pol: polychaetes; mol: molluscs; cru: crustaceans; ech: echinoderms; 
Table 3. Local abundance of the most dominant species. Sites are ordered in a sequence from south to north. *Highest dominance within a single site $(47.5 \%)$

\begin{tabular}{|lccc|}
\hline Site & $\begin{array}{c}\text { Amphiura } \\
\text { filiformis }\end{array}$ & $\begin{array}{c}\text { Chaetozone } \\
\text { setosa }\end{array}$ & $\begin{array}{c}\text { Myriochele } \\
\text { oculata }\end{array}$ \\
\hline Hod24 & 87 & 17 & $439^{*}$ \\
Hod11 & 103 & 23 & 104 \\
Val12 & 22 & 9 & 87 \\
Val24 & 51 & 18 & 18 \\
Reg4 & 101 & 10 & 16 \\
Val19 & 72 & 26 & 27 \\
Eldb10 & 59 & 45 & 17 \\
Tom6 & 47 & 24 & 26 \\
Reg7 & 66 & 37 & 25 \\
Eko11 & 28 & 18 & 54 \\
Eko42 & 51 & 3 & 10 \\
Reg6 & 65 & 103 & 12 \\
Reg2 & 77 & 55 & 4 \\
Gyd22 & 56 & 50 & 7 \\
Reg5 & 62 & 353 & 15 \\
Ula22 & 58 & 165 & 15 \\
\hline
\end{tabular}

groups showed more variability than the species richness, especially for the polychaetes (Fig. 2A,B,C). Generally, polychaetes had the highest local heterogeneity diversity, with the exception of some sites, explained by high dominance of the polychaetes Myriochele oculata and Chaetozone setosa (see Table 3). The diversity of the polychaetes was highest at the mid-range sites in the south-north sequence. Species richness was not correlated with ExpH' or 1/Simpson, but these 2 indices were closely positively correlated (Spearman rank correlation coefficient $r_{s}=0.95, p=0.0001, n=16$, see Table 2), even though they measure different aspects of species diversity.

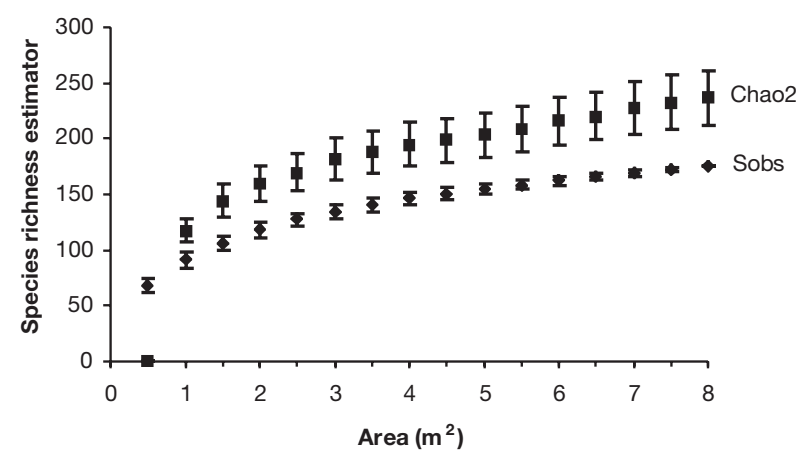

Fig. 3. Species accumulation curves. Estimators of species richness are the total number of all species (Sobs) and the Chao2 estimator of true richness. Plotted values are mean \pm SD of 100 estimates based on 100 randomisations of sample accumulation order (without replacement). Fitting a regression to the number of species gives Sobs $=92.03+90.01 \times$ $\left(\mathrm{LOG}_{10}\right.$ area in $\left.\mathrm{m}^{2}\right)$ with $\mathrm{r}=0.999$

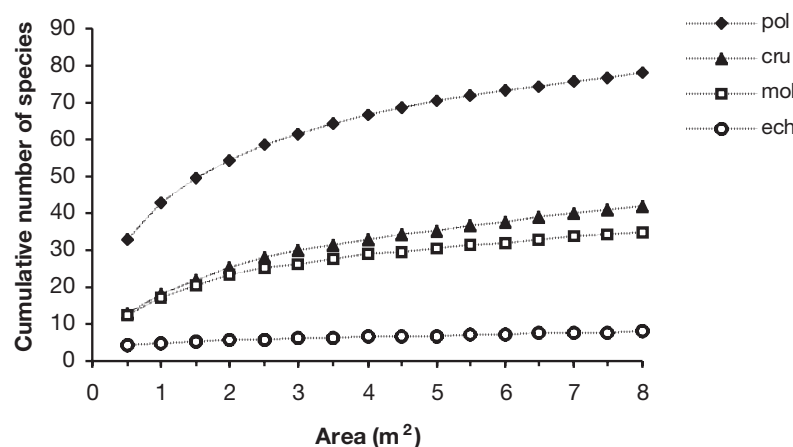

Fig. 4. Cumulative number of species plotted against area $\left(\mathrm{m}^{2}\right)$ within dominant taxonomic groups. Plotted values are means of 100 estimates based on 100 randomisations of sample accumulation order (without replacement). See Fig. 2 for abbreviations

Estimates of cumulative species richness against area showed little sign of approaching asymptotic values (Fig. 3). The total number of species observed was 175, while the Chao2 estimate of species richness gave $236 \pm 24$ (mean $\pm \mathrm{SD})$. The polychaetes $(78$ species $)$ constituted $45 \%$ of the total number of species, whereas the crustaceans ( 42 species), molluscs (35 species) and echinoderms (8 species) constituted 24, 20, and $5 \%$, respectively. The low number of echinoderms reached an asymptotic value. However, the species accumulation curves for the other groups did not stabilise towards asymptotic values (Fig. 4).

\section{Abundance and species range sizes}

The cumulative dominance of the 10 most abundant species in the study area was $64.6 \%$ (Table 4). Dominance of single species across the whole data set had a maximum of $10.9 \%$ (Amphiura filiformis), and the 10th most dominant species comprised $3.7 \%$. Maximum dominance within 1 site was occasionally much higher, ranging from 10.4 to $47.5 \%$. The echinoderm $A$. filiformis was abundant in the whole study area, Chaetozone setosa had the highest abundance in the northern

Table 4. Dominance patterns across the whole data set

\begin{tabular}{|lccc|}
\hline Species & N & $\begin{array}{c}\text { Dominance } \\
(\%)\end{array}$ & $\begin{array}{c}\text { Cumulative } \\
\text { dominance (\%) }\end{array}$ \\
\hline Amphiura filiformis & 1005 & 10.87 & 10.87 \\
Chaetozone setosa & 956 & 10.34 & 21.22 \\
Myriochele oculata & 876 & 9.48 & 30.69 \\
Eudorellopsis deformis & 714 & 7.72 & 38.42 \\
Phoronis sp. & 508 & 5.50 & 43.91 \\
Ophiura affinis & 428 & 4.63 & 48.54 \\
Spiophanes bombyx & 401 & 4.34 & 52.88 \\
Spiophanes kroeyeri & 389 & 4.21 & 57.09 \\
Mysella bidentata & 353 & 3.82 & 60.91 \\
Scoloplos armiger & 337 & 3.65 & 64.56 \\
\hline
\end{tabular}




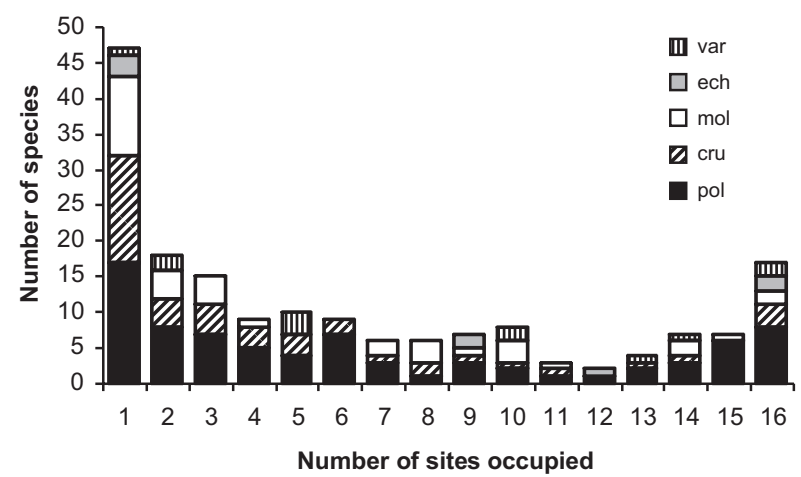

Fig. 5. Distribution of species range sizes within taxonomic groups. Range size is the number of sites occupied by a species out of a total of 16 sites (cf. Fig. 1). See Fig. 2 for abbreviations

part (Reg5, Ula22, and Reg6), whereas Myriochele oculata was the most dominant species in the southern part (Hod24, Hod11, and Val12) (Table 3). The abundance of C. setosa in a single grab ranged from 8 to 66 individuals out of a total of 307 individuals in 10 grabs at Ula22. Likewise, at Hod 24 the abundance of $M$. oculata in a single grab ranged from 6 to 242 individuals out of a total of 586 individuals in 10 grabs.

Seventeen species, or $10 \%$ of the total number of species recorded, spanned the entire sampling area of 16 sites (Fig. 5). These species were among the 25 most abundant and were dominated by polychaetes $(47 \%)$, whereas the proportion of crustaceans, molluscs, and echinoderms was lower, at 18,12 , and $12 \%$, respectively. Conversely, 47 species, or $27 \%$ of the total number of species, were uniques (restricted to a single site). Thirtysix percent of the uniques were polychaetes, whereas the proportion of crustaceans, molluscs, and echinoderms was 32,23 , and $6 \%$, respectively. The uniques had low abundances, where 39 species ( $83 \%$ ) were singletons (only 1 individual at a site), 3 species were dubletons ( 2 individuals), and the remaining 5 species had only 3 individuals. Eighteen species were restricted to only 2 sites (duplicates). Only $22 \%$ of the total number of polychaetes were found at a single site only, while as much as $36 \%$ of the crustaceans, $31 \%$ of the molluscs, and $38 \%$ ( 3 species) of the echinoderms were uniques. Species range size was positively correlated with local abundance within the dominant taxonomic groups (Table 5). Thus, common species were widely spatially distributed, while species of low abundance had strongly compressed range sizes. There was a clear positive correlation between the total number of species and the number of unique species (product-moment correlation coefficient, $\mathrm{r}=0.76, \mathrm{p}=0.001, \mathrm{n}=16$ ). The number of singletons was also related to the total number of species $(r=0.56, p=0.023, n=16)$. However, there was no significant correlation between the num-
Table 5. Interspecific relations between local abundance and range size within dominant taxonomic groups. Measure of correlation is Spearman rank correlation (all coefficients are significant at $\mathrm{p}<0.05$ )

\begin{tabular}{|lrrr|}
\hline Taxonomic group & $\mathrm{n}$ & \multicolumn{2}{c|}{$\begin{array}{c}\text { Local abundance versus } \\
\text { range size }\end{array}$} \\
& & $\mathrm{r}_{\mathrm{s}}$ & $\mathrm{p}$ \\
\hline Polychaeta & 78 & 0.77 & $<0.001$ \\
Crustacea & 42 & 0.74 & $<0.001$ \\
Mollusca & 35 & 0.70 & $<0.001$ \\
Echinodermata & 8 & 0.85 & 0.008 \\
& & & \\
\hline
\end{tabular}
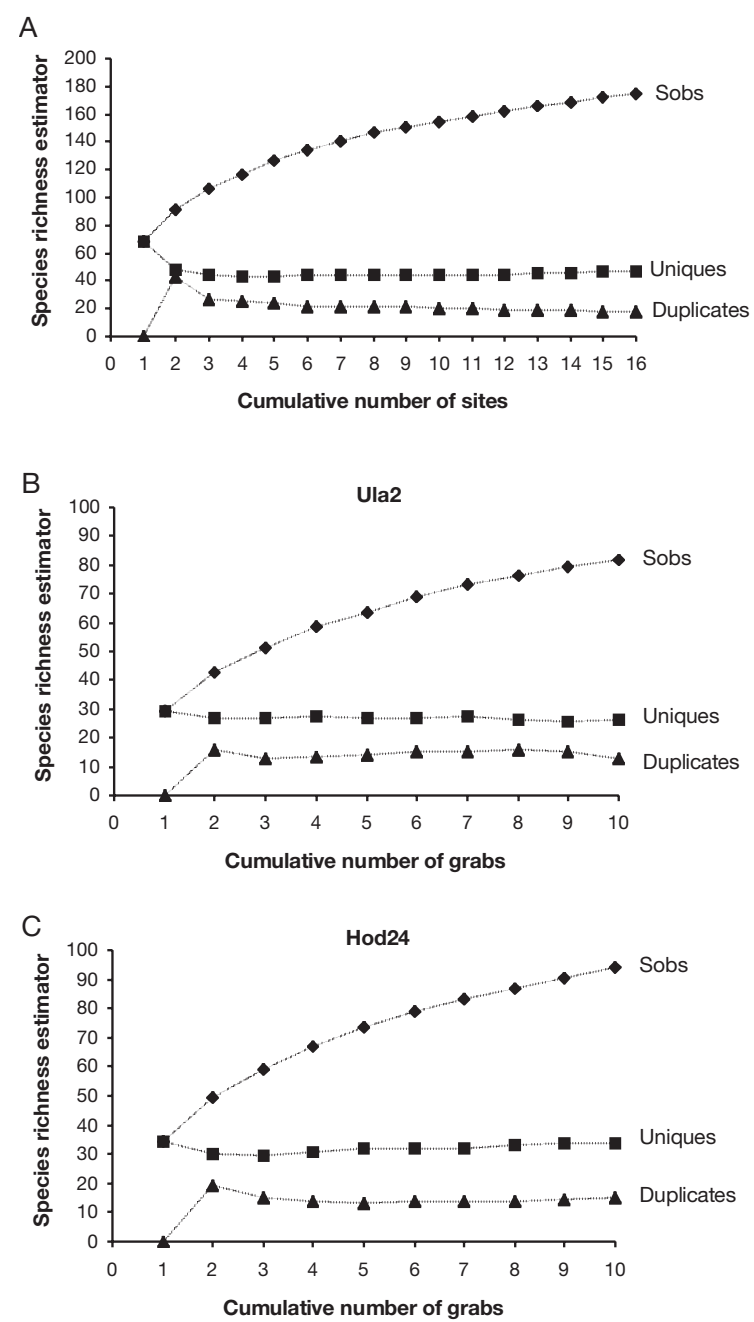

Fig. 6. Species accumulation curves. Estimators of richness are the total number of species (Sobs), the number of species restricted to a single site or grab (uniques), and the number of species found at exactly 2 sites or grabs only (duplicates). Plotted values are means of 50 estimates based on 50 randomisations of sample accumulation order (without replacement). (A) 16 sites from the whole sampling area, (B) 10 replicated sampling units (grabs) from the northernmost site in the study area (Ula22), (C) 10 grabs from the southernmost site $(\operatorname{Hod} 24)$ 


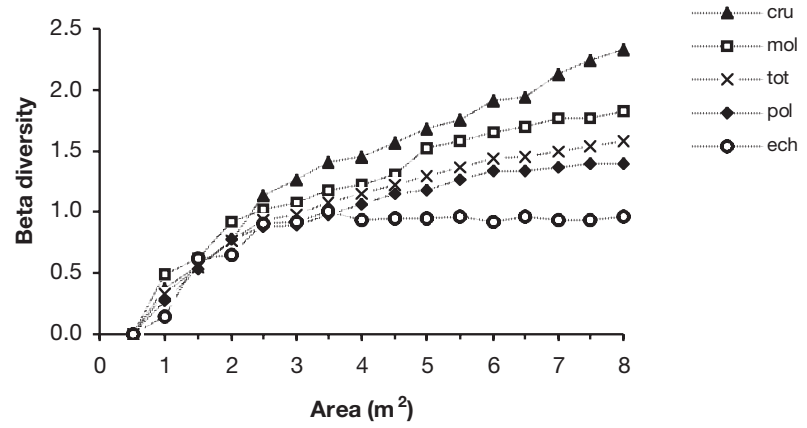

Fig. 7. Cumulative beta diversity $\left(\beta_{W}\right)$ plotted against area $\left(\mathrm{m}^{2}\right)$ within dominant taxonomic groups and for all taxa pooled. Samples ordered in a sequence from south to north in the study area. tot: total (all taxa pooled). See Fig. 2 for other abbreviations

ber of uniques and the number of singletons per site $(\mathrm{r}=0.33, \mathrm{p}=0.207, \mathrm{n}=16)$.

Fig. 6A shows that more widespread species were added with increasing sampling coverage rather than restricted-range species. The cumulative number of uniques and duplicates showed a rapid approach to an asymptote, whereas total species richness did not. The same pattern appeared at a local scale when the species richness estimators were plotted against the number of sampling units (Fig. 6B,C). Thus, species that appear to have restricted range in a small data set of few sites or sampling units might actually seem to be more widespread if sampling effort or area is increased. The number of species restricted to a single grab (uniques) was $34(36.2 \%)$ out of a total of 94 species in 10 grabs at Hod24 and 26 (31.7\%) out of a total of 82 at Ula22.

\section{Beta diversity}

Total $\beta_{\mathrm{W}}$ varied between taxonomic groups and was highest for crustaceans (2.3), followed by molluscs (1.8), polychaetes (1.4), and echinoderms (1.0) (Fig. 7). The overall $\beta_{\mathrm{W}}$ for all taxonomic groups pooled was rel-

Table 6. Relations between latitude and pairwise beta diversity $\left(\beta_{\mathrm{W}}\right)$ between adjacent sites within dominant taxonomic groups and for all taxa pooled in a sequence from south to north in the study area. Measure of correlation is Spearman rank correlation $\left(r_{s}\right)$ with significant $(p<0.05)$ coefficients in bold ( $\mathrm{n}=15$ for all correlations)

\begin{tabular}{|lcc|}
\hline Taxonomic group & \multicolumn{3}{c|}{ Pairwise $\beta_{\mathrm{W}}$ versus latitude } \\
& $\mathrm{r}_{\mathrm{s}}$ & $\mathrm{p}$ \\
\hline Polychaeta & -0.23 & 0.412 \\
Crustacea & 0.17 & 0.540 \\
Mollusca & -0.48 & 0.070 \\
Echinodermata & -0.44 & 0.232 \\
All taxa & $\mathbf{- 0 . 5 4}$ & 0.038 \\
\hline
\end{tabular}

atively low (1.6). For all taxa pooled there was a negative correlation between latitude and pairwise $\beta_{\mathrm{W}}$ between adjacent sites in a sequence from south to north $\left(\mathrm{r}_{\mathrm{s}}=-0.54, \mathrm{p}=0.038, \mathrm{n}=15\right)$ (Table 6). Thus, species turnover between adjacent sites was lower further north. Neither the measured environmental variables nor $\alpha$ diversity was correlated with latitude (Table 2), so the decrease in pairwise $\beta_{\mathrm{W}}$ in the south-north sequence could not be attributed to such gradients. However, no significant relation was found between latitude and pairwise $\beta_{\mathrm{W}}$ for each of the dominant taxonomic groups (Table 6).

The number of species in common between all pairwise combinations of sites was relatively high, ranging from 35 to 54 species, but not correlated with spatial distance between sites $(r=-0.04, p=0.638, n=120)$ (Fig. 8A). Thus, adjacent sites (nearest neighbours) did
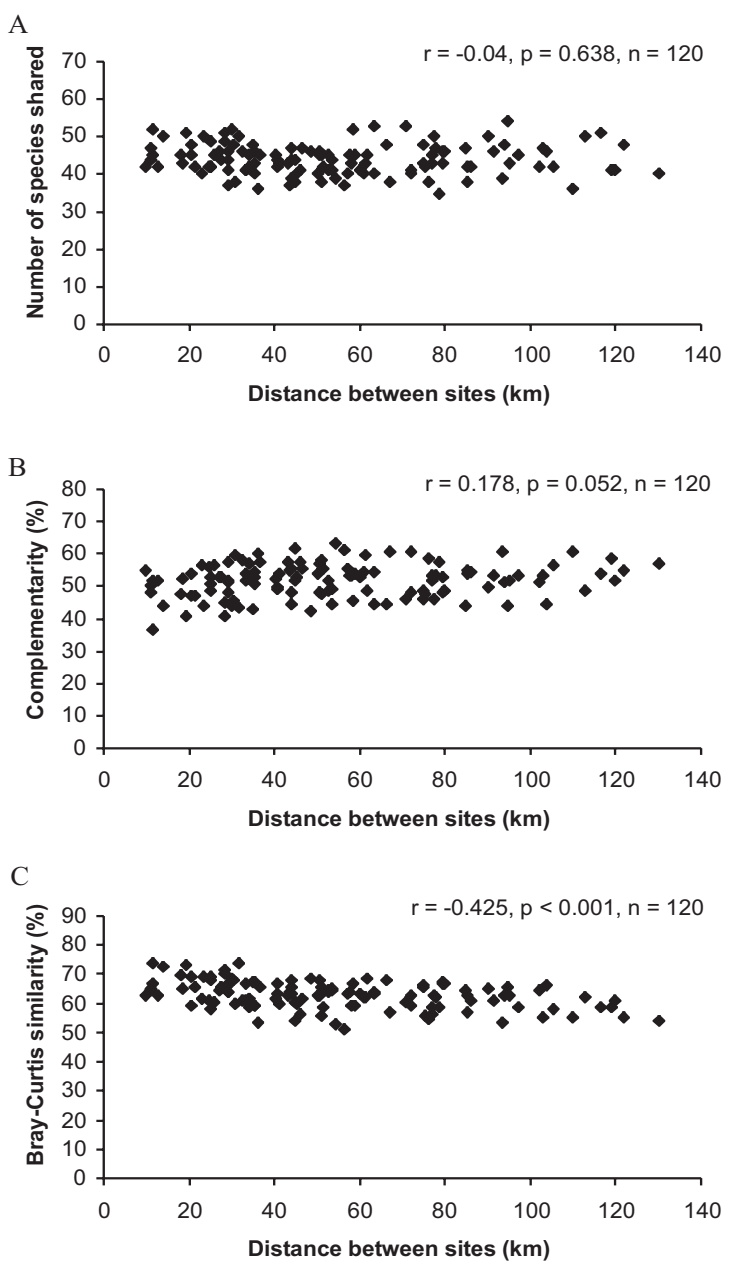

Fig. 8. Beta diversity across sites. Measure of correlation between beta diversity and distance between sites is the product-moment correlation coefficient r. (A) The number of species common between all pairwise permutations of sites over the total area sampled, (B) Complementarity (biotic distinctness, \%) between all pairwise combinations of sites, (C) BrayCurtis similarity (\%) between all pairwise permutations of sites 
not on average share significantly more species than site pairs further apart, even though the maximum distance between sites was as much as $130 \mathrm{~km}$. The complementarity values showed a relatively low to moderate level of distinctness between all pairwise combinations of sites (37 to $63 \%$ distinct), but was not correlated with distance between sites $(r=0.178, p=0.052, n=120)$ (Fig. 8B). This shows that biotic distinctness between adjacent sites was not on average lower than between site pairs further apart. However, the Bray-Curtis similarity between all pairwise permutations of sites, ranging from 51 to $74 \%$, was negatively correlated with distance $(\mathrm{r}=$ $-0.425, \mathrm{p}<0.001, \mathrm{n}=120$ ) (Fig. $8 \mathrm{C}$ ). Although this correlation was not strong, this indicates that adjacent sites had higher similarity on average than site pairs further apart. There was an overall significance in the Mantel correlogram, based on the Bray-Curtis similarity matrix, since 2 of the individual values exceed the Bonferronicorrected significance level $(\alpha / k=0.05 / 8=0.006$, where $k$ is the number of distance classes) (Fig. 9). There was significant positive autocorrelation in the small distance classes (1 to 2) and significant negative autocorrelation in the large classes (7 to 8). The overall shape of this correlogram could be attributed to a faunal gradient, a result that is in accordance with the multivariate measure of $\beta$ diversity in Fig. 8C.

\section{Faunal assemblages in space and relations with environmental variables}

Multidimensional scaling ordination and clustering, based on Bray-Curtis similarities from square root transformed abundances, are shown in Fig. 10A,B. With the exception of 2 single sites (Hod24 and Val12), virtually all clustering took place over a tight range of similarities (65 to $75 \%$ ). Despite the tight range of similarities between the sites, the 2 multivariate analyses gave additional information to the univariate mea-

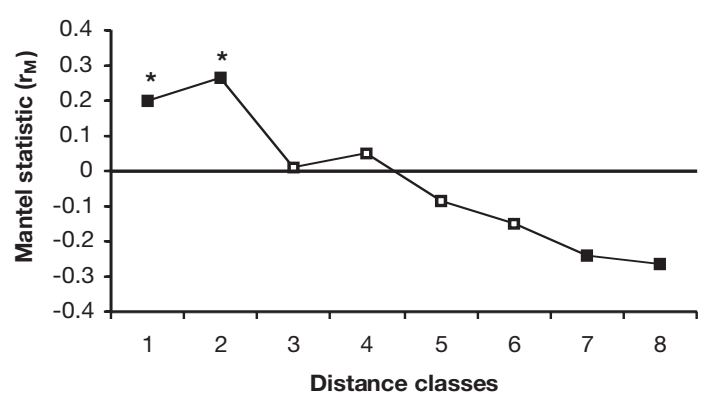

Fig. 9. Mantel correlogram. The 8 distance classes were created with equal width, where 1 unit of distance is about $16 \mathrm{~km}$. Dark squares represent significant values of the Mantel statistic $(p<0.05)$. ${ }^{*}$ Value exceeds the Bonferronicorrected significance level $(\alpha / k=0.05 / 8=0.006$, where $k$ is the number of distance classes)
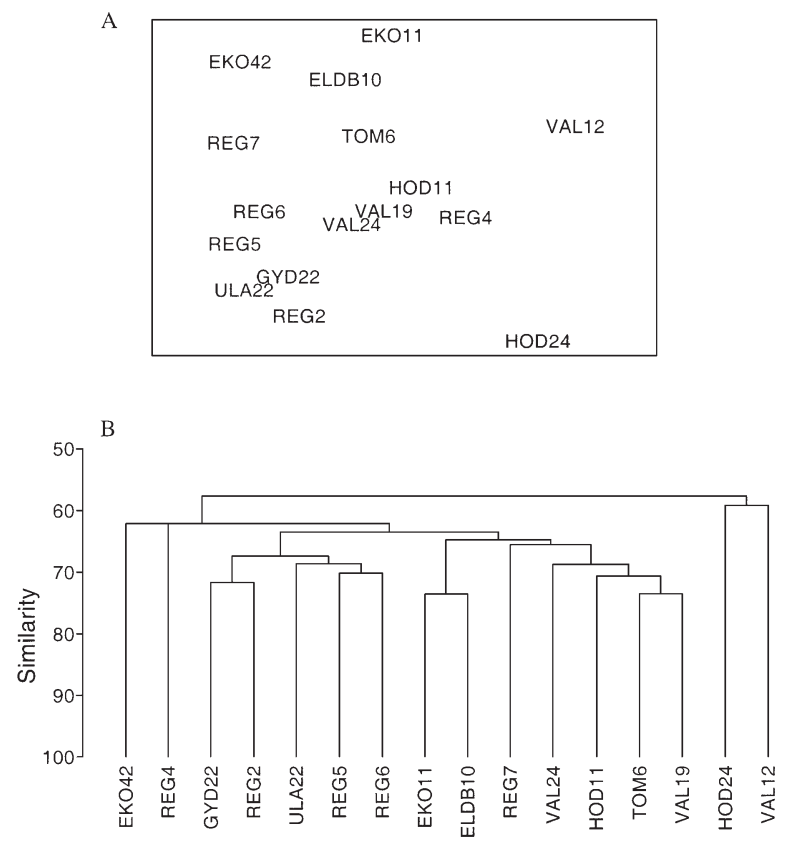

Fig. 10. (A) Multidimensional scaling ordination for square root transformed macrobenthos data based on Bray-Curtis similarities (stress $=0.15$ ), (B) hierarchical, agglomerative clustering of square root macrobenthos data using groupaverage linking on Bray-Curtis similarities (\%)

sures of community structure. An important feature is the relative proximity of the 5 northernmost sites to each other on the ordination plot, despite their wide geographic range (Fig. 1). Conversely, the distances between the 3 southernmost sites Hod24, Hod11, and Val12 on the ordination plot show that they had more different community patterns, despite the relatively small geographic distances between them.

As the Spearman rank correlation analysis (Table 2) of environmental variables showed that no variables were highly correlated (all correlations $<0.95$ ), all variables were used in the BIO-ENV analysis, the results of which are summarised in Table 7 . The relations between individual environmental factors and square root transformed abundance data were generally weak (range of $r_{s}=0.39$ to -0.02 ). Latitude showed a higher degree of correlation with the faunal composition $\left(\mathrm{r}_{\mathrm{s}}=\right.$ 0.39 ) than the other single factors and 'explained' the faunal patterns better than any subset of environmental variables. Adding further variables degraded the correlation.

\section{Faunal pattern and variability and relations with scales}

At the local scale (i.e. a single site) the variability in heterogeneity diversity among 10 replicated grabs was 
Table 7. Summary of results from the BIO-ENV analysis. Combinations of variables, $k$ at a time, giving the highest $r_{\mathrm{s}}$ between biotic and abiotic similarity matrices; bold type indicates the highest correlation. Lower correlations are omitted from the table. Biotic data square root transformed, abiotic data $\log (1+\mathrm{N})$ transformed with the exception of latitude, longitude and depth. Siltclay: fraction of sediment $<0.063 \mathrm{~mm}(\%) ; S k_{I}$ : skewness; $\sigma_{I}$ : sorting; Lat: latitude; Long: longitude

\begin{tabular}{|llll|}
\hline$k$ & & Best variable combinations & \\
\hline 1 & Lat (0.39) & $\sigma_{I}(0.26)$ & Long $(0.19)$ \\
2 & Lat, Long (0.38) & Lat, $\sigma_{I}(0.32)$ & Lat, Depth $(0.31)$ \\
3 & Lat, Long, Depth (0.37) & Lat, Long, Silt-clay $(0.36)$ & Lat, Long, $\sigma_{I}(0.34)$ \\
4 & Lat, Long, Depth, Silt-clay (0.36) & Lat, Long, Depth, $S k_{I}(0.34)$ & Lat, Long, Depth, $\sigma_{I}(0.33)$ \\
\hline
\end{tabular}

Table 8. Diversity measures at local (a single site), intermediate and regional scale (whole study area). At intermediate and regional scale each site is the sum of five $0.1 \mathrm{~m}^{2}$ grabs $\pm 95 \%$ confidence intervals (CI). COV: coefficient of variation (standard deviation/mean) multiplied by $100 \%$; ${ }^{*} 10$ grabs (each $0.1 \mathrm{~m}^{2}$ ) at 1 site; S: the number of species; ExpH': the exponentiated form of the Shannon formula; 1/Simpson: the reciprocal of Simpson's index; Ula22: the northernmost site; Hod24: the southernmost site

\begin{tabular}{|c|c|c|c|c|c|c|c|c|c|c|}
\hline Scale & No. of sites & Latitude & Longitude & $S$ mean & $\stackrel{S}{\mathrm{COV}}$ & Total $S$ & $\begin{array}{c}\text { ExpH' } \\
\text { mean }\end{array}$ & $\begin{array}{c}E x p H^{\prime} \\
\text { COV }\end{array}$ & $\begin{array}{c}\text { 1/Simpson } \\
\text { mean }\end{array}$ & $\begin{array}{l}\text { 1/Simpson } \\
\text { COV }\end{array}$ \\
\hline Regional & 16 & $56^{\circ} 02^{\prime}-57^{\circ} 08^{\prime}$ & $2^{\circ} 30^{\prime}-3^{\circ} 49^{\prime}$ & $67.81 \pm 3.49$ & 9.67 & 175 & $25.21 \pm 3.95$ & 29.41 & $14.28 \pm 3.08$ & 40.49 \\
\hline Intermediate & 16 & $56^{\circ} 19^{\prime}-56^{\circ} 26^{\prime}$ & $3^{\circ} 12^{\prime}-3^{\circ} 16^{\prime}$ & $66.31 \pm 3.14$ & 8.87 & 144 & $29.08 \pm 1.70$ & 10.95 & $17.44 \pm 1.69$ & 18.14 \\
\hline Intermediate & 8 & $56^{\circ} 28^{\prime}-56^{\circ} 30^{\prime}$ & $2^{\circ} 54^{\prime}-2^{\circ} 55^{\prime}$ & $68.50 \pm 2.79$ & 4.87 & 134 & $35.14 \pm 2.60$ & 8.87 & $22.10 \pm 2.46$ & 13.33 \\
\hline Local & $1^{*}$ & \multicolumn{2}{|c|}{ Ula22 } & $29.40 \pm 2.55$ & 12.13 & 82 & $14.66 \pm 2.07$ & 19.73 & $8.65 \pm 2.05$ & 33.05 \\
\hline Local & $1^{*}$ & \multicolumn{2}{|c|}{ Hod24 } & $34.30 \pm 3.71$ & 15.12 & 94 & $15.66 \pm 4.66$ & 41.62 & $9.11 \pm 3.94$ & 60.42 \\
\hline
\end{tabular}

high (Table 8). The average number of species in 10 grabs at Hod24 was 34 out of a total of 94 recorded, while the average number at Ula22 was 29 out of a total of 82 species. Furthermore, the average BrayCurtis similarity among the 10 grabs at Ula22 and Hod24 was low (56.2 and $56.5 \%$, respectively). This shows that a single grab would not be representative of 1 site. The number of species in the first 5 grabs pooled was $76(80.9 \%)$ at Hod24 and $61(74.4 \%)$ at Ula22. Thus, pooling data across grabs evens out the high

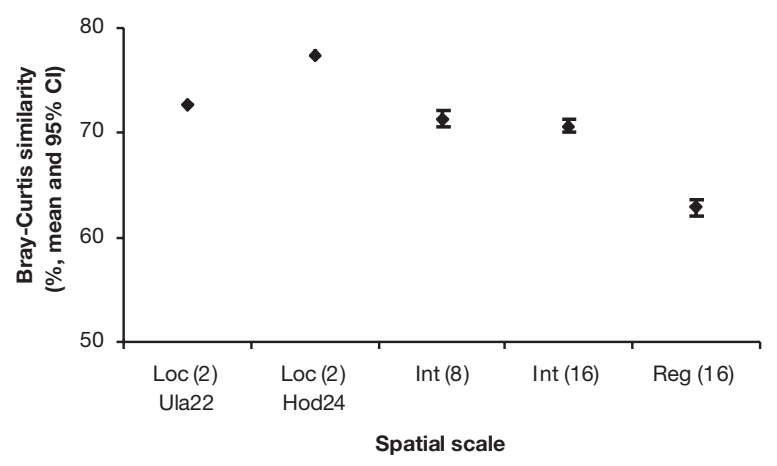

Fig. 11. Bray-Curtis similarity (\%), given as mean and 95\% confidence interval (CI) of biotic data from different geographic scales. At local scale the similarity is between the sum of 5 grabs selected at random and the sum of the remaining 5 grabs. The number of sites or samples (i.e. sum of 5 grabs) at each scale is given in parenthesis. Hod24: the southernmost site; Ula22: the northernmost site; Loc: local scale (1 site); Int: intermediate scale; Reg: regional scale (whole study area) variability among them and gives a more representative picture of the community structure at a site. Data sets from 3 different scales are compared in Fig. 11. At local scale 5 grabs were selected at random and the Bray-Curtis similarity between the sum of these grabs and the sum of the remaining 5 grabs was, respectively, 77.3 and $72.7 \%$ at Hod24 and Ula22 (Fig. 11). The average Bray-Curtis similarity between sites (i.e. sum of 5 grabs) was higher at intermediate (about $71 \%)$ than at the regional scale (62.8\%) (Fig. 11). Thus, the faunal pattern changed with scales. Furthermore, the biotic variability was higher at regional than at intermediate scales (Table 8). Thus, the variability also changed with scales.

In the data set from the whole study area, the average Bray-Curtis similarity between sites decreased significantly with increasing geographic scale, starting at the northernmost site (Ula22) of the area and including more and more sites in the data set (Fig. 12A). The unit of increase in scale was $25 \mathrm{~km}$ in all directions from this 'start site'. However, contrary to expectation, there was no significant change in average similarity with increasing scale, starting at the southernmost site (Hod24) (Fig. 12B). Thus, there were different patterns depending on the start site. This can be explained by the fact that the average similarity between the sites in the southern part (located relatively close to each other) was not higher than the average similarity between all pairwise combinations of sites in the whole study area. The southernmost sites were more dissimi- 
A

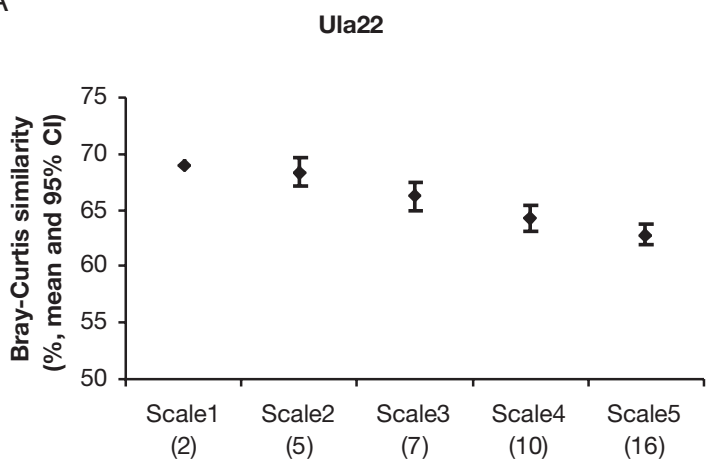

B

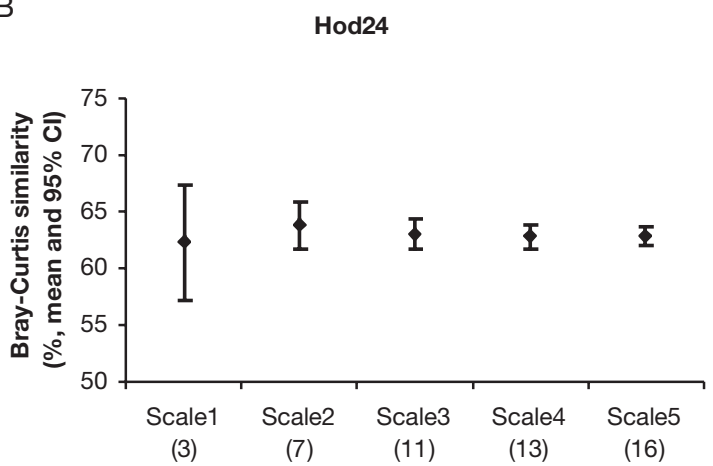

Fig. 12. Bray-Curtis similarity (\%) given as mean and 95\% CI of biotic data sets with increasing geographic scale (i.e. increasing number of sites, Scale 1 to 5). The unit of increase in scale is $25 \mathrm{~km}$ in all directions from a 'start site'. The number of sites at each scale is given in parentheses. (A) The start site is the northernmost site in the study area (Ula22), (B) the start site is the southernmost site $(\operatorname{Hod} 24)$

lar to each other than the sites in the northern part, a pattern also illustrated by the classification and ordination techniques (Fig. 10A,B).

\section{DISCUSSION}

\section{Species richness and rarity - the 2 common measurements}

The heterogeneity diversity (ExpH' and 1/Simpson) of the 4 dominant taxonomic groups showed more variability than the species richness. The diversity of the polychaetes was highest at the mid-range sites in a sequence from south to north in the area. This can be explained by the high dominance of Myriochele oculata and Chaetozone setosa in, respectively, the southern and northern part of the study area (especially at Hod24, Reg5, and Ula22). C. setosa has been reported to increase in abundance in areas affected by oil or gas activities in the North Sea (Gray et al. 1990, Olsgard \& Gray 1995), and both species are common in the tran- sition zone along a gradient of organic enrichment (Pearson \& Rosenberg 1978). However, as the measured metal and total hydrocarbon concentrations at Hod24, Reg5, and Ula22 were low (Mannvik et al. 1997), the high local abundance of these species in the present study was more likely to be the result of natural factors rather than oil or gas activities. Moreover, Kirkegaard (1969) found that M. oculata and C. setosa were common throughout the North Sea during the years 1950 to 1955, before any oil or gas activities.

The brittle star Amphiura filiformis was abundant in the whole study area and had the highest dominance across the whole data set. A. filiformis has been reported to decrease in abundance in areas affected by oil or gas activities in the North Sea (Olsgard \& Gray 1995). This again indicates that the dominant species were typical of non-polluted areas. A. filiformis and many of the other benthic invertebrates found in the present study have planktonic dispersal (see references in Josefson 1986). Widespread dispersal of planktonic larvae is largely regarded as passive transport by water currents (Butman 1987).

Butman (1987) discussed large spatial scale processes such as passive deposition and small scale processes such as active habitat selection in determining larval settlement of soft-sediment invertebrates. In a study of corals along the Great Barrier Reef, Hughes et al. (1999) proposed that much of the variation in patterns of recruitment occurred at the time of settlement, at both large and small scales. In the present study the abundance of Chaetozone setosa and Myriochele oculata varied considerably between single grabs at a site and between sites in the study area. According to Levin (1992) ecological systems exhibit heterogeneity and patchiness on a broad range of scales, and the distribution of any species is patchy on a range of scales.

The actual number of species in a given soft-sediment area is usually not measurable, and a central problem for any sampling-based study is to estimate to what extent the values obtained from sampling represent the reality. Neither the species accumulation curve nor the Chao2 estimates reached asymptotic values in the present study (16 sites). Thus, there was no sign of having collected all the potential species, and the Chao 2 value was almost certainly an underestimate. In a study of polychaetes in the Pacific Paterson et al. (1998) suggested that Chao 2 gave a reasonable estimate of the likely number of species at a site of 47 samples. However, the species accumulation curve did not reach an asymptote, despite extensive sampling. They reported that at 2 other sites of 15 and 16 samples, neither Chao2 nor the species accumulation curves reached asymptotic values. The data presented here are similar and suggest that a larger number of samples are needed before Chao 2 gives a reliable esti- 
mate in marine soft sediments. Subtidally, where sediments tend to grade into each other and the extent of a habitat or assemblage often cannot be determined, the species accumulation curves may not necessarily reach asymptotic values. As sampling area is increased so is the number of slightly different patches. Colwell \& Coddington (1994) suggested that for terrestrial studies as few as 12 samples would enable a useful Chao2 estimate. Differences between marine and terrestrial studies may result from methodology and what constitutes a sample in the respective environments (Paterson et al. 1998). The Chao2 method is based on the total number of species observed in addition to the frequency of occurrence of uniques and duplicates. In this study 47 species were uniques and 18 were duplicates, and this group of 65 restricted-range species comprised a significant fraction of the benthos (37\%). The fact that species of low abundance at any 1 site, regardless of the number of sites at which they occur, have a low probability of being recorded because they are more difficult to detect (Brown 1984, Gaston 1994) may distort the results. With insufficient sampling intensity, species may appear to occur at fewer sites or have lower abundance.

The most species-rich sites contained significantly more rare species, with regard to both range size and abundance. From terrestrial studies there is also evidence that areas of high species richness are those rich in restricted-range species, thus supporting arguments for conservation of species-rich habitats (Thomas \& Mallorie 1985, Kerr 1997). However, this assumption does not always hold either in terrestrial (Prendergast et al. 1993) or in marine systems (Schlacher et al. 1998). Therefore, a strategy based on the selection of a limited number of species-rich areas does not guarantee effective conservation of rare species because a large proportion of them might occur outside the speciesrich areas. The finding, in this study, of a positive relation between range size and local abundance holds for many different groups of species over a variety of spatial scales and appears to be general (Brown 1984). According to Brown (1984) it is highly unlikely that all areas are equally favourable for all species, and therefore it is more realistic to assume that the differences in abundance and spatial distribution are primarily the result of different requirements and tolerances. However, any correlation between range size and abundance should be treated cautiously because a possible explanation for this pattern is undersampling of rare species.

Polychaetes were the most common taxonomic group and had the highest proportion of widespread species. Crustaceans were more restricted in their distribution (i.e. had smaller range sizes) than the other dominant taxonomic groups, and molluscs were more restricted than polychaetes. The fact that many crustaceans are mobile, and hence may be undersampled because they are able to move away from the grab, may distort the result. Echinoderms were represented by only 8 species, and are therefore not given much weight in the following discussions. In summary, common species were widely spatially distributed, while species of low abundance had strongly compressed range sizes. The number of rare species was positively correlated with species richness. As the distribution of species varied between the dominant taxonomic groups more than 1 group should be studied in a system.

\section{Beta diversity - a component of biodiversity}

Alpha and beta diversity measure together the overall diversity or biotic heterogeneity of an area (Wilson \& Shmida 1984). Since $\beta$ diversity is $\gamma$ divided by $\alpha$ (Whittaker 1960) or alternatively $\gamma$ minus $\alpha$ (Loreau 2000) we also need $\gamma$ diversity. Local richness and biotic differences are positive components of biodiversity, whereas biotic similarity is negatively related to overall biodiversity (Colwell \& Coddington 1994). Wilson \& Shmida (1984) state that $\beta_{\mathrm{W}}$ is perhaps the most widely used measure of $\beta$ diversity. In the present study the overall $\beta_{\mathrm{W}}$ varied between the dominant taxonomic groups and was highest for crustaceans, followed by molluscs and polychaetes. The findings that crustaceans and molluscs also had higher relative proportions of unique species than polychaetes suggests that $\beta$ diversity measures are highest in those taxonomic groups with the highest proportion of restricted-range species. However, the few echinoderms recorded in this study are an exception to this suggested relation.

The number of shared species and the complementarity were independent of spatial scale, whereas BrayCurtis similarity was a function of spatial arrangement. In these measures the identities of the species is taken into account, in contrast to the $\beta_{\mathrm{W}}$ measure. Distance between sites may be associated with differences in environmental variables, confounding the interpretation of distance effects (Harrison et al. 1992), but in this study the habitat was uniform. There was a general agreement among these 3 measures that $\beta$ diversity in the area was relatively low to moderate.

The complementarity of 2 samples can be overestimated and the number of shared species underestimated because an undersampled species tends to occur in fewer samples than it should (Colwell \& Coddington 1994). Schlacher et al. (1998) found in a study of macrobenthos in a coral lagoon that the number of shared species between all pairwise permutations of sites was low (i.e. high $\beta$ diversity), but weakly correlated with distance. In a study of polychaetes in the Atlantic and 
Pacific Paterson et al. (1998) showed that change in faunal composition (species turnover) is related to distance. However, the number of published studies that have explored any patterns in $\beta$ diversity is small (Gaston \& Williams 1996), and interactions between $\beta$ diversity-distance and $\beta$ diversity-habitat change are ecologically interesting, but no generalisations have been derived as yet (Harrison et al. 1992). To summarise, studies of $\beta$ diversity gave information additional to local species richness and estimates of total species richness. The $\beta_{\mathrm{W}}$ varied among the dominant taxonomic groups and was highest for crustaceans, which had a high proportion of restricted range species. The multivariate measure of $\beta$ diversity, the Bray-Curtis similarity, was most sensitive to community differences between sites within the single habitat type.

\section{Faunal pattern and variability and the importance of spatial scales}

Universal definitions of local and regional scales do not exist, and according to Harrison et al. (1992) the choice is entirely arbitrary. However, the scale of the local habitat depends on the taxon in question and generally increases for taxa having larger body sizes and wider home ranges (Cornell \& Lawton 1992). Gaston (1994) defined local scale as 'a small area of homogeneous habitat' and regional scale as 'an area large enough to embrace many habitats, but not so large as to encompass the geographic ranges of a significant proportion of the species in an assemblage'. Defining what is a habitat in soft sediments is not a simple task, and in addition no habitat is truly homogeneous (Colwell \& Coddington 1994). In the present study the sediment grain size and depth were rather uniform over the whole area and I regard this as a single habitat. Thrush et al. (1997a) considered 3 separate components of scale: 'grain', the area of an individual sample; 'lag', the intersample distance; and 'extent', the total area over which samples were collected. In the present study I used a site as local scale and the whole study area as regional scale, corresponding to grain and extent, respectively.

The spacing between replicates in soft-sediment studies is generally in the order of a few meters, but the actual distance is often unknown and varies with water depth and water movements. The replicates do not necessarily come from the same type of patch because of small-scale spatial variation. A single grab, covering only $0.1 \mathrm{~m}^{2}$, is known to sample only a small fraction of the species at a site. Thus, neither local species richness nor diversity can be estimated from a single grab. Therefore, data from 5 grabs pooled together were used to give a more meaningful measure of local scale biodiversity. Harrison et al. (1992) used $2500 \mathrm{~km}^{2}$ as a local scale at which they measured $\alpha$ diversity, yet following Whittaker (1960) $\alpha$ diversity was described over a scale of only a few $\mathrm{m}^{2}$ in the present study (i.e. 1 sample or site). As the ecological processes that affect these 2 scales must be different (Gray 2000), the pattern and variability will also be different.

According to Levin (1992) there is no single correct scale at which ecosystems should be described. However, it is difficult to scale up from the results of smallscale surveys to conclusions that are relevant to ecological patterns and processes at larger spatial scales (Thrush \& Warwick 1997). Cross-scale studies are critical to complement more traditional studies carried out on narrow single scales (Levin 1992). More care is needed in the selection of appropriate spatial scales for sampling before conclusions about differences in faunal pattern from one place to another can be reached (Morrisey et al. 1992). Furthermore, a comparison of only a few samples may be insufficient in a study of latitudinal gradients in the marine system (Gray 2000). In this study the Bray-Curtis similarity between samples (i.e. sum of 5 grabs) was highest at the local scale and lowest at the regional scale. The biotic variability between sites was lower at intermediate than at the regional scale. Thus, the faunal pattern and variability changed with scales. However, the southernmost sites were more dissimilar to each other than the sites in the northern part. Thus, the faunal pattern changed across space in the study area, despite the uniform habitat. In summary, the measurement and assessment of marine biodiversity depend on spatial scale, and a comparison of only a few sites between areas is insufficient. The knowledge of community diversity and differences within a single habitat type is needed to differentiate among habitats.

Acknowledgements. I thank John S. Gray for discussion of many of the ideas presented in this paper and Frode Olsgard, Pierre Legendre, and Simon F. Thrush for further fruitful discussions. Thanks also to PPCoN, Amoco, BP, and Statoil for allowing me to use the Region I data in this analysis, and to Akvaplan-niva AS and Det Norske Veritas for preparing the data set.

\section{LITERATURE CITED}

Anonymous (1990) Manual for overvåkingsundersøkelser rundt petroleumsinstallasjoner i norske havområder. Statens Forurensningstilsyn (SFT) Report no. 90:01 (in Norwegian)

Bray JR, Curtis JT (1957) An ordination of the upland forest communities of southern Wisconsin. Ecol Monogr 27: $325-349$

Brown JH (1984) On the relationship between abundance and distribution of species. Am Nat 124:255-279

Butman CA (1987) Larval settlement of soft-sediment inverte- 
brates: the spatial scales of pattern explained by active habitat selection and the emerging role of hydrodynamical processes. Oceanogr Mar Biol Ann Rev 25:113-165

Chao A (1987) Estimating the population size for capturerecapture data with unequal catchability. Biometrics 43: 783-791

Clarke KR, Ainsworth M (1993) A method of linking multivariate community structure to environmental variables. Mar Ecol Prog Ser 92:205-219

Clarke KR, Green RH (1988) Statistical design and analysis for a 'biological effects' study. Mar Ecol Prog Ser 46: 213-226

Clarke KR, Warwick RM (1994) Change in marine communities: an approach to statistical analysis and interpretation. Plymouth Marine Laboratory, Plymouth

Clifford DHT, Stephenson W (1975) An introduction to numerical classification. Academic Press, New York

Colwell RK (1997) EstimateS: statistical estimation of species richness and shared species from samples. Version 5. User's guide and application. Available at: http://viceroy. eeb.uconn. edu/estimates

Colwell RK, Coddington JA (1994) Estimating terrestrial biodiversity through extrapolation. Philos Trans R Soc Lond 345:101-118

Cornell HV, Lawton JH (1992) Species interactions, local and regional processes, and limits to the richness of ecological communities: a theoretical perspective. J Anim Ecol 61: $1-12$

Gaston KJ (1994) Rarity. Chapman and Hall, London

Gaston KJ (1996) What is biodiversity? In: Gaston KJ (ed) Biodiversity. A biology of numbers and difference. Blackwell Science Ltd, Oxford, p 1-9

Gaston KJ, Williams PH (1996) Spatial patterns in taxonomic diversity. In: Gaston KJ (ed) Biodiversity. A biology of numbers and difference. Blackwell Science Ltd, Oxford, p 202-229

Gray JS (1974) Animal-sediment relationships. Oceanogr Mar Biol Ann Rev 12:223-261

Gray JS (1997) Marine biodiversity: patterns, treats and conservation needs. Biodiv Conserv 6:153-175

Gray JS (2000) The measurement of marine species diversity, with an application to the benthic fauna of the Norwegian continental shelf. J Exp Mar Biol Ecol 250:23-49

Gray JS, Clarke KR, Warwick RM, Hobbs G (1990) Detection of initial effects of pollution on marine benthos: an example from the Ekofisk and Eldfisk oilfields, North Sea. Mar Ecol Prog Ser 66:285-299

Harper JL, Hawksworth DL (1994) Biodiversity: measurement and estimation. Preface. Philos Trans R Soc Lond 345:5-12

Harrison S, Ross SJ, Lawton JH (1992) Beta diversity on geographic gradients in Britain. J Anim Ecol 61:151-158

Heip C, Warwick R, d'Ozouville L (1998) A European science plan on marine biodiversity. European Marine and Polar Science (EMaPS), European Science Foundation (ESF), Strasbourg

Heywood VH, Watson RT (1995) Global biodiversity assessment. Cambridge University Press, Cambridge

Hill MO (1973) Diversity and evenness: a unifying notation and its consequences. Ecology 54:427-432

Hughes TP, Baird AH, Dinsdale EA, Moltschaniwskyl NA, Pratchett MS, Tanner JE, Willis BL (1999) Patterns of recruitment and abundance of corals along the Great Barrier Reef. Nature 397:59-63

Josefson AB (1986) Temporal heterogeneity in deep-water soft-sediment benthos - an attempt to reveal temporal structure. Estuar Coast Shelf Sci 23:147-169

Kerr JT (1997) Species richness, endemism, and the choice of areas for conservation. Conserv Biol 11:1094-1100
Kirkegaard JB (1969) A quantitative investigation of the central North Sea polychaeta. Spolia 29:8-285

Kruskal JB, Wish M (1978) Multidimensional scaling. Sage Publications, Beverly Hills

Legendre P, Fortin MJ (1989) Spatial pattern and ecological analysis. Vegetatio 80:107-138

Legendre P, Legendre L (1998) Numerical ecology. Developments in environmental modelling 20. Elsevier, Amsterdam

Legendre P, Vaudor A (1991) The R Package: multidimensional analysis, spatial analysis. Département de sciences biologiques, Université de Montréal, Montréal

Levin SA (1992) The problem of pattern and scale in ecology. Ecology 73:1943-1967

Loreau M (2000) Are communities saturated? On the relationship between $\alpha, \beta$ and $\gamma$ diversity. Ecol Lett 3:73-76

Magurran AE (1988) Ecological diversity and its measurement. Croom Helm, London

Mannvik HP, Pearson T, Pettersen A, Lie Gabrielsen K (1997) Environmental monitoring survey. Region I 1996. Main report. Akvaplan-niva AS/Unilab analyse AS, Tromsø

May RM (1994) Biological diversity: differences between land and sea. Philos Trans R Soc Lond B Biol Sci 343:105-111

Morrisey DJ, Howitt L, Underwood AJ, Stark JS (1992) Spatial variation in soft-sediment benthos. Mar Ecol Prog Ser 81: 197-204

Oden NL, Sokal RR (1986) Directional autocorrelation: an extension of spatial correlograms to two dimensions. Syst Zool 35:608-617

Olsgard F, Gray JS (1995) A comprehensive analysis of the effects of offshore oil and gas exploration and production on the benthic communities of the Norwegian continental shelf. Mar Ecol Prog Ser 122:277-306

Paterson GLJ, Wilson GDF, Cosson N, Lamont PA (1998) Hessler and Jumars (1974) revisited: abyssal polychaete assemblages from the Atlantic and Pacific. Deep-Sea Res 45:225-251

Pearson T, Rosenberg R (1978) Macrobenthic succession in relation to organic enrichment and pollution of the marine environment. Oceanogr Mar Biol Annu Rev 16:229-311

Peet RK (1974) The measurement of species diversity. Annu Rev Ecol Syst 5:285-307

Prendergast JR, Quinn RM, Lawton JH, Eversham C, Gibbons DW (1993) Rare species, the coincidence of diversity hotspots and conservation strategies. Nature 365:335-337

Sanders HL (1968) Marine benthic diversity: a comparative study. Am Nat 102:243-282

Schlacher TA, Newell P, Clavier J, Schlacher-Hoenlinger MA, Chevillon C, Britton J (1998) Soft-sediment benthic community structure in a coral reef lagoon - the prominence of spatial heterogeneity and 'spot endemism'. Mar Ecol Prog Ser 174:159-174

Snelgrove PVR (1999) Getting to the bottom of marine biodiversity: sedimentary habitats. Ocean bottoms are the most widespread habitat on earth and support high biodiversity and key ecosystem services. BioScience 49:129-138

Snelgrove PVR, Blackburn TH, Hutchings PA, Alongi DM, Grassle JF, Hummel H, King G, Koike I, Lambshead PJD, Ramsing NB, Solis-Weiss V (1997) The importance of marine sediment biodiversity in ecosystem processes. Ambio 26:578-583

Sokal RR (1986) Spatial data analysis and historical processes. In: Diday E, Escoufier Y, Lebart L, Pages JP, Schektman Y, Tomassone R (eds) Data analysis and informatics. NorthHolland, Amsterdam, p 29-43

Thomas CD, Mallorie HC (1985) Rarity, species richness and conservation: butterflies of the Atlas Mountains in Morocco. Biol Conserv 33:95-117 
Thrush SF, Warwick RM (1997) The ecology of soft-bottom habitats: matching spatial patterns with dynamic processes. J Exp Mar Biol Ecol 216:ix

Thrush SF, Pridmore RD, Bell RG, Cummings VJ, Dayton PK, Ford R, Grant J, Green MO, Hewitt JE, Hines AH, Hume TM, Lawrie SM, Legendre $\mathrm{P}$, McArdle BH, Morrisey D, Schneider DC, Turner SJ, Walters RA, Whitlatch RB, Wilkinson MR (1997a) The sandflat habitat: scaling from experiments to conclusions. J Exp Mar Biol Ecol 216:1-9

Thrush SF, Schneider DC, Legendre P, Whitlatch RB, Dayton PK, Hewitt JE, Hines AH, Cummings VJ, Lawrie SM, Grant J, Pridmore RD, Turner SJ, McArdle BH (1997b) Scaling-up from experiments to complex ecological systems: where to next? J Exp Mar Biol Ecol 216:243-254

Ward TJ, Kenchington RA, Faith DP, Margules CR (1998)

Editorial responsibility: Otto Kinne,

Oldendorf/Luhe, Germany
Marine BioRap guidelines: rapid assessment of marine biological diversity. CSIRO, Perth

Warwick RM, Clarke KR (1991) A comparison of some methods for analysing changes in benthic community structure. J Mar Biol Assoc UK 71:225-244

Warwick RM, Clarke KR (1993) Comparing the severity of disturbance: a meta-analysis of marine macrobenthic community data. Mar Ecol Prog Ser 92:221-231

Whittaker RH (1960) Vegetation of the Siskiyou Mountains, Oregon and California. Ecol Monogr 30:279-338

Whittaker RH (1972) Evolution and measurement of species diversity. Taxon 21:213-251

Whittaker RH (1975) Communities and ecosystems. Macmillan, New York

Wilson MV, Shmida A (1984) Measuring beta diversity with presence-absence data. J Ecol 72:1055-1064

Submitted: September 27, 2000; Accepted: January 9, 2001

Proofs received from author(s): July 20, 2001 